\title{
A Severe Presentation of Plasma Cell Cheilitis
}

\author{
Leah Cohen, MD; Jessica M. Farahi, MD; Merrick A. Brodsky, MD; Whitney A. High, MD, JD, MEng; \\ Jeremy Hugh, MD
}

\section{PRACTICE POINTS}

- Plasma cell cheilitis (PCC) is a benign condition that affects the lower lip in older individuals, presenting as a nonspecific, red-brown patch or plaque that can progress slowly to erosions and edema.

- Our patient with PCC experienced full resolution of symptoms with application of a class I topical corticosteroid.
Plasma cell cheilitis (PCC) is an uncommon condition characterized by mature plasma cell infiltration of the dermis of the mucosal lip. The condition often presents as a red-brown patch or plaque on the lower lip in older individuals that can progress to erosions and edema. Diagnosis can be delayed because clinical findings are nonspecific and can mimic neoplastic, infectious, and inflammatory conditions. We describe a patient with PCC who presented to our institution via teledermatology. Findings were equivocal on 2 early biopsies until the presentation evolved to dramatic ulceration and necrosis, which prompted a third biopsy that was diagnostic for PCC. Empiric therapy with a class I topical corticosteroid was successful.

Cutis. 2021;108:E28-E31.

$\longrightarrow 1$ lasma cell cheilitis (PCC), also known as plasmocytosis circumorificialis and plasmocytosis mucosae, ${ }^{1}$ is a poorly understood, uncommon inflammatory condition characterized by dense infiltration of mature plasma cells in the mucosal dermis of the lip..$^{2-5}$ The etiology of PCC is unknown but is thought to be a reactive immune process triggered by infection, mechanical friction, trauma, or solar damage. . $^{1,5,6}$

The most common presentation of PCC is a slowly evolving, red-brown patch or plaque on the lower lip in older individuals. ${ }^{2,3,5,7}$ Secondary changes with disease progression can include erosion, ulceration, fissures, edema, bleeding, or crusting. ${ }^{5}$ The diagnosis of PCC is challenging because it can mimic neoplastic, infectious, and inflammatory conditions. ${ }^{8,9}$

Treatment strategies for PCC described in the literature vary, as does therapeutic response. Resolution of PCC has been documented after systemic steroids, intralesional steroids, systemic griseofulvin, and topical calcineurin inhibitors, among other agents. ${ }^{6,7,10-16}$

We present the case of a patient with a lip lesion who ultimately was diagnosed with PCC after it progressed to an advanced necrotic stage.

\section{Case Report}

An 80-year-old male veteran of the Armed Services initially presented to our institution via teledermatology with redness and crusting of the lower lip (Figure 1). He had a history of myelodysplastic syndrome and anemia requiring iron transfusion. The process appeared to be consistent with actinic cheilitis vs squamous cell carcinoma. In-person dermatology

Dr. Cohen is from the Department of Dermatology, Florida International University Herbert Wertheim College of Medicine, Miami. Drs. Farahi, Brodsky, High, and Hugh are from the Department of Dermatology, University of Colorado Anschutz Medical Campus, Aurora. Dr. High also is from the Department of Dermatopathology.

The authors report no conflict of interest.

Correspondence: Jeremy Hugh, MD, 1665 Aurora Ct, Aurora, CO 80045 (jeremy.hugh@cuanschutz.edu).

doi:10.12788/cutis.0341 
consultation was recommended; however, the patient did not follow through with that appointment.

Five months later, additional photographs of the lesion were taken by the patient's primary care physician and sent through teledermatology, revealing progression to an erythematous, yellow-crusted erosion (Figure 2). The medical record indicated that a punch biopsy performed by the patient's primary care physician showed hyperkeratosis and fungal organisms on periodic acidSchiff staining. He subsequently applied ketoconazole and terbinafine cream to the lower lip without improvement. Prompt in-person evaluation by dermatology was again recommended.

Ten days later, the patient was seen in our dermatology clinic, at which point his condition had rapidly progressed. The lower lip displayed a $3.0 \times 2.5-\mathrm{cm}$, yellow and black, crusted, ulcerated plaque (Figure 3). He reported severe burning and pain of the lip as well as spontaneous bleeding. He had lost approximately 10 pounds over

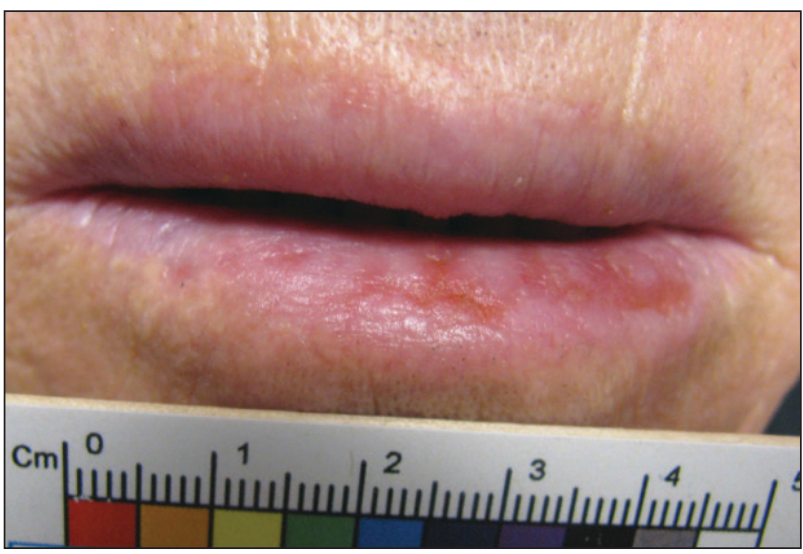

FIGURE 1. III-defined, red-brown patch of shallow erosions on the lower lip at the initial presentation.

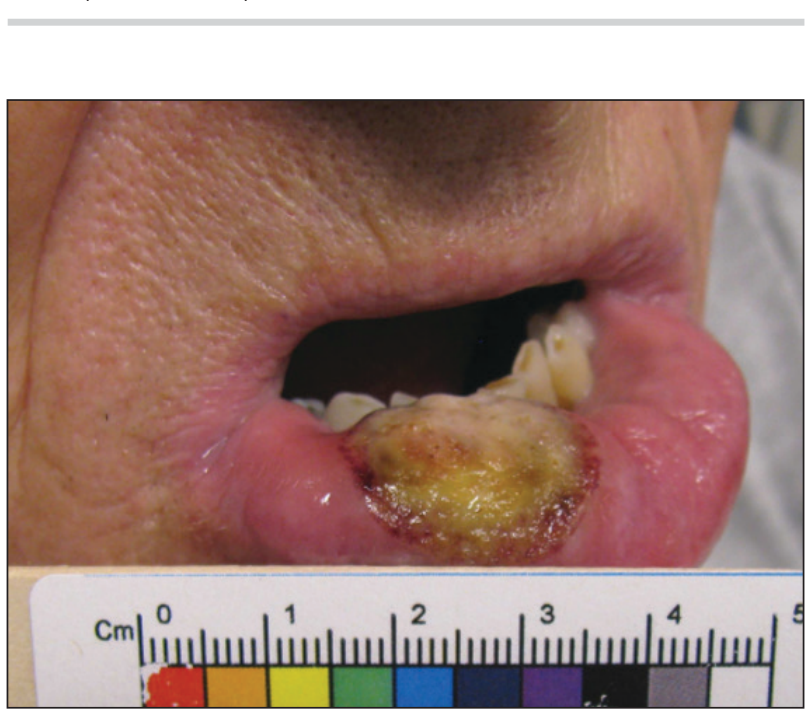

FIGURE 2. Well-defined, 2.0-cm, erythematous, yellow-crusted erosion on the right lower lip 5 months after the initial presentation. the last month due to poor oral intake. A second punch biopsy showed benign mucosa with extensive ulceration and formation of full-thickness granulation tissue. No fungi or bacteria were identified.

Consultation and Histologic AnalysisDermatopathology was consulted and recommended a third punch biopsy for additional testing. A repeat biopsy demonstrated ulceration with lateral elements of retained epidermis and a dense submucosal chronic inflammatory infiltrate comprising plasma cells and lymphocytes (Figures 4 and 5). Immunohistochemical staining demonstrated a mixed inflammatory infiltrate with $\mathrm{CD}^{+} \mathrm{T}$ cells and $\mathrm{CD} 20^{+} \mathrm{B}$ cells. In situ hybridization studies demonstrated numerous lambda-positive and kappa-positive plasma cells without chain restriction. Periodic acid-Schiff with diastase and Grocott-Gomori methenamine-silver staining demonstrated no fungi. Findings were interpreted to be most consistent with a diagnosis of PCC.

Treatment and Follow-up - The patient was treated with clobetasol ointment $0.05 \%$ twice daily for 6 weeks and topical lidocaine as needed for pain. At 6-week followup, he displayed substantial improvement, with normalappearing lips and complete resolution of symptoms.

\section{Comment}

The diagnosis and management of PCC is difficult because the condition is uncommon (though its true incidence is unknown) and the presentation is nonspecific, invoking a wide differential diagnosis. In the literature, PCC presents as a slowly progressive, red-brown patch or plaque on the lower lip in older individuals. ${ }^{2,3,5,7}$ The lesion can progress to become eroded, ulcerated, fissured, or edematous. ${ }^{5}$

Differential Diagnosis-The clinical differential diagnosis of PCC is broad and includes inflammatory, infectious, and neoplastic causes, such as actinic cheilitis, allergic contact cheilitis, exfoliative cheilitis, granulomatous cheilitis,

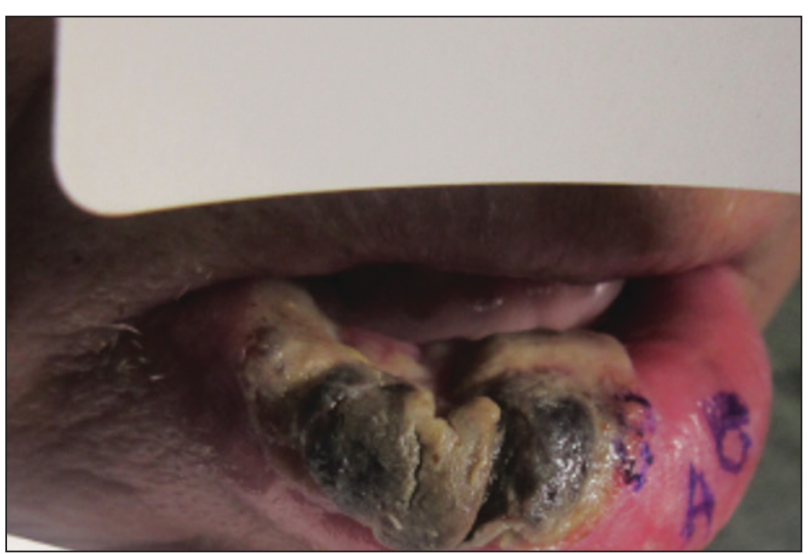

FIGURE 3. After 10 days, the lesion progressed to a well-defined, $3.0 \times 2.5-\mathrm{cm}$, yellow and black, crusted, ulcerated plaque on the right lower lip. Punch biopsy sites were selected at the margin of the plaque. 


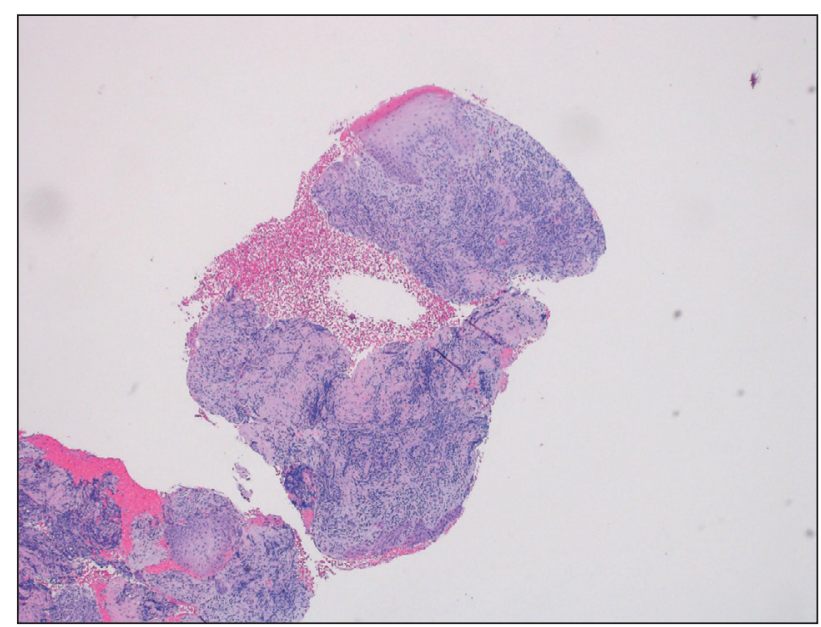

FIGURE 4. A repeat biopsy demonstrated ulceration with lateral elements of retained epidermis and a dense submucosal chronic inflammatory infiltrate $(H \& E$, original magnification $\times 2)$.

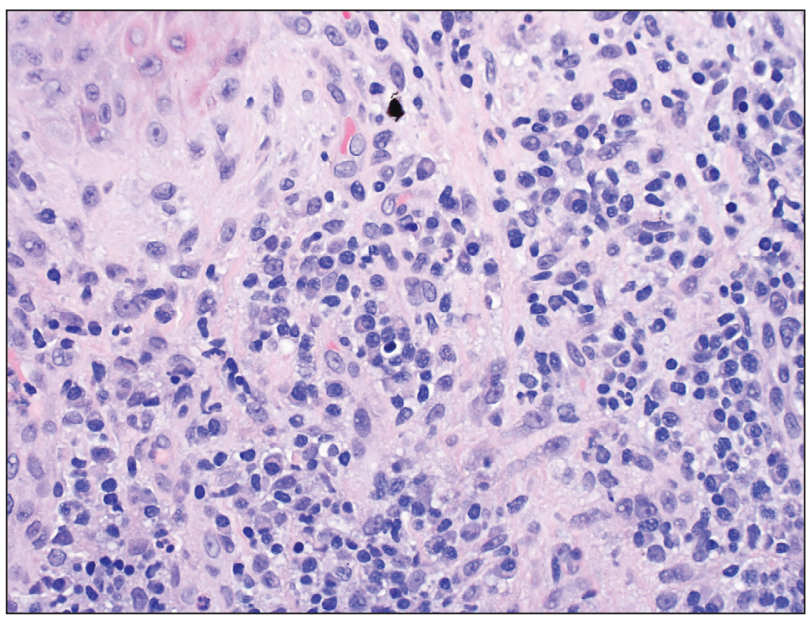

FIGURE 5. On higher magnification, the inflammatory infiltrate was noted to comprise plasma cells and lymphocytes (H\&E, original magnification $\times 20$ ).

lichen planus, candidiasis, syphilis, and squamous cell carcinoma of the lip. ${ }^{7,9}$ The histologic differential diagnosis includes allergic contact cheilitis, secondary syphilis, actinic cheilitis, squamous cell carcinoma, cheilitis granulomatosa, and plasmacytoma. ${ }^{17-19}$

Histopathology-On biopsy, PCC usually is characterized by plasma cells in a bandlike pattern in the upper submucosa or even more diffusely throughout the submucosa. ${ }^{20}$ In earlier studies, polyclonality of plasma cells with kappa and lambda light chains has been demonstrated ${ }^{5}$; in this case, such polyclonality militated against a plasma cell dyscrasia. There have been reports of a various number of eosinophils in PCC, ${ }^{5,20}$ but eosinophils were not a prominent feature in our case.

Treatment-As reported in the literature, treatment of PCC has been attempted using a broad range of strategies; however, the optimal regimen has yet to be elucidated. ${ }^{15}$ Numerous therapies, including excision, radiation, electrocauterization, cryotherapy, steroids, systemic griseofulvin, topical fusidic acid, and topical calcineurin inhibitors, have yielded variable success. ${ }^{6,7010-16}$

The success of topical corticosteroids, as demonstrated in our case, has been unpredictable; the reported response has ranged from complete resolution to failure. ${ }^{9}$ This variability is thought to be related to epithelial width and the degree of acanthosis, with ulcerative lesions demonstrating a superior response to topical corticosteroids. ${ }^{9}$

\section{Conclusion}

Our case highlights the challenges of diagnosing and managing PCC, especially through teledermatology. Initial photographs of the lesion (Figure 1) that were submitted demonstrated a nonspecific erosion, which was concerning for any of several infectious, inflammatory, and malignant causes. Prompt in-person evaluation was warranted; regrettably, the patient's condition worsened rapidly in the 10 days it took for him to be seen in-person by dermatology.

Furthermore, this case necessitated 3 separate biopsies because the pathology on the first 2 biopsies initially was equivocal, demonstrating ulceration and granulation tissue. The diagnosis was finally made after a third biopsy was recommended by a dermatopathologist, who eventually identified a bandlike distribution of polyclonal plasma cells in the upper submucosa, consistent with a diagnosis of PCC. Our patient's final disease presentation (Figure 3) was exuberant and may represent the end point of untreated PCC.

\section{REFERENCES}

1. Senol M, Ozcan A, Aydin NE, et al. Intertriginous plasmacytosis with plasmoacanthoma: report of a typical case and review of the literature. Int J Dermatol. 2008;47:265-268. doi:10.1111/j.1365 $-4632.2008 .03385 . x$

2. Rocha N, Mota F, Horta M, et al. Plasma cell cheilitis. J Eur Acad Dermatol Venereol. 2004;18:96-98. doi:10.1111/j.1468 -3083.2004.00791.x

3. Farrier JN, Perkins CS. Plasma cell cheilitis. Br J Oral Maxillofac Surg. 2008;46:679-680. doi:10.1016/j.bjoms.2008.03.009

4. Baughman RD, Berger P, Pringle WM. Plasma cell cheilitis. Arch Dermatol. 1974;110:725-726.

5. Lee JY, Kim KH, Hahm JE, et al. Plasma cell cheilitis: a clinicopathological and immunohistochemical study of 13 cases. Ann Dermatol. 2017;29:536-542. doi:10.5021/ad.2017.29.5.536

6. da Cunha Filho RR, Tochetto LB, Tochetto BB, et al. "Angular" plasma cell cheilitis. Dermatol Online J. 2014;20:doj_21759.

7. Yang JH, Lee UH, Jang SJ, et al. Plasma cell cheilitis treated with intralesional injection of corticosteroids. J Dermatol. 2005;32:987-990. doi:10.1111/j.1346-8138.2005.tb00887.x

8. Solomon LW, Wein RO, Rosenwald I, et al. Plasma cell mucositis of the oral cavity: report of a case and review of the literature. Oral Surg Oral Med Oral Pathol Oral Radiol Endod. 2008;106:853-860. doi:10.1016/j. tripleo.2008.08.016

9. Dos Santos HT, Cunha JLS, Santana LAM, et al. Plasma cell cheilitis: the diagnosis of a disorder mimicking lip cancer. Autops Case Rep. 2019;9:e2018075. doi:10.4322/acr.2018.075

10. Fujimura T, Furudate S, Ishibashi M, et al. Successful treatment of plasmacytosis circumorificialis with topical tacrolimus: two case reports and an immunohistochemical study. Case Rep Dermatol. 2013;5:79-83. doi:10.1159/000350184 
11. Tamaki K, Osada A, Tsukamoto K, et al. Treatment of plasma cell cheilitis with griseofulvin. J Am Acad Dermatol. 1994;30:789-790. doi:10.1016/ s0190-9622(08)81515-0

12. Choi JW, Choi M, Cho KH. Successful treatment of plasma cell cheilitis with topical calcineurin inhibitors. J Dermatol. 2009;36:669-671. doi:10.1111/j.1346-8138.2009.00733.x

13. Hanami $Y$, Motoki $Y$, Yamamoto T. Successful treatment of plasma cell cheilitis with topical tacrolimus: report of two cases. Dermatol Online J. 2011;17:6

14. Jin $\mathrm{SP}$, Cho KH, Huh CH. Plasma cell cheilitis, successfully treated with topical 0.03\% tacrolimus ointment. J Dermatolog Treat. 2010;21:130-132. doi:10.1080/09546630903200620

15. Tseng JT-P, Cheng C-J, Lee W-R, et al. Plasma-cell cheilitis: successful treatment with intralesional injections of corticosteroids. Clin Exp Dermatol. 2009;34:174-177. doi:10.1111/j.1365-2230.2008.02765.x
16. Yoshimura K, Nakano S, Tsuruta D, et al. Successful treatment with 308$\mathrm{nm}$ monochromatic excimer light and subsequent tacrolimus $0.03 \%$ ointment in refractory plasma cell cheilitis. J Dermatol. 2013;40:471-474. doi:10.1111/1346-8138.12152

17. Fujimura $Y$, Natsuga $K$, Abe $R$, et al. Plasma cell cheilitis extending beyond vermillion border. J Dermatol. 2015;42:935-936. doi:10.1111/1346-8138.12985

18. White JW Jr, Olsen KD, Banks PM. Plasma cell orificial mucositis. report of a case and review of the literature. Arch Dermatol. 1986;122:1321-1324. doi:10.1001/archderm .122 .11 .1321

19. Román CC, Yuste CM, Gonzalez MA, et al. Plasma cell gingivitis. Cutis. 2002;69:41-45

20. Choe HC, Park HJ, Oh ST, et al. Clinicopathologic study of 8 patients with plasma cell cheilitis. Korean J Dermatol. 2003;41:174-178. 